\title{
Correction to: The Not So Exemplary Example - Bangladesh National Police
}

\author{
Heath B. Grant, Shanna O'Reilly, and Staci Strobl
}

\section{Correction to:}

Chapter 6 in: H. B. Grant, Police Integrity in the Developing World, SpringerBriefs in Criminology, https://doi.org/10.1007/978-3-030-00413-2_6

The original version of the chapter was inadvertently published without including the co-authors' names. The following names have now been included in the chapter opening page.

Heath B. Grant, Shanna O’Reilly, and Staci Strobl 